\title{
Procés de digitalització d'un projecte de Física contextualitzada de batxillerat
}

\author{
Luisa Herreras $\bowtie$ Institut Guillem de Berguedà (Berga) \\ i Josep Olivella, Institut Llobregat (Sallent)
}

La Física en Context és un projecte que proposa una nova metodologia per a l'ensenyament de la Física de Batxillerat basada en contextos. En aquest article es fa una revisió de com ha evolucionat aquest projecte fins arribar al format digital actual, com s'està aplicant actualment i quines són algunes de les dificultats que es troba el professorat que aplica aquest projecte.

Paraules clau: física, batxillerat, context, digital, treball en grup

\section{Introducció}

Des del CESIRE CDEC s'ha promogut la creació d'uns materials educatius de física, química i biologia de batxillerat completament adaptats als currículums actuals LOE marcats pel Departament d'Ensenyament de la Generalitat de Catalunya. Proposen una nova metodologia basada en contextos de la vida quotidiana que han de permetre l'alumnat veure com la ciència no és aliena a la societat que l'envolta.

L'Informe Rocard (Rocard, M. et al., 2007) es fa ressò del creixent desencís que presenta l'alumnat envers les ciències. Com una de les possibles causes d'aquest fenomen l'informe apunta a la manera com s'ensenyen les ciències. El propi informe fa una sèrie de recomanacions entre les quals destaca l'afavorir un canvi metodològic i la creació i manteniment de xarxes de comunicació entre els docents.

A partir del treball fet en el marc de la llicència d'estudis "Adequació del projecte Física en Context a l'aplicatiu de recobriment curricular (ARC)" (OliveIla, 2011), s'han elaborat uns materials educatius per a la matèria de Física de Batxillerat que recullen les orientacions marcades per l'informe Rocard. Els materials s'adeqüen també a algunes de les actuacions prioritàries del Departament d'Ensenyament com per exemple la que fa referència a l'elaboració de materials curriculars en format digital sota llicència Creative Commons accessibles a tot el professorat i a l'alumnat.

\section{La Física en Context}

La Física en Context va néixer el curs 20032004 com una adaptació del projecte anglès "Salters-Horners, Advanced Physics" (2001), duta a terme per un grup de treball de professors del CESIRE-CDEC. Aquests materials van ser experimentats per professors en diferents centres de tot Catalunya que es reunien periòdicament per a fer-ne l'avaluació.

D'aquest procés neix la llicència d'estudis "Avaluació del procés d'implementació de l'adaptació a Catalunya del Projecte Física Salters-Horners $i$ propostes de modificació" (Herreras, 2007), duta a terme per la professora Luisa Herreras durant el curs 2007-2008. Els resultats d'aquest treball van ser de gran ajuda a l'hora d'enfocar la contextualització dels continguts, analitzar l'adequació de les activitats d'aprenentatge proposades, esbrinar quines són les motivacions del professorat en l'aplicació del projecte per poder potenciar-les, detectar problemes en l'aplicació a l'aula, plantejar les accions necessàries per millorar el projecte i ampliar la seva implementació, i elaborar d'aquesta manera uns materials de més qualitat.

Tots aquests resultats van ser claus per a l'elaboració de les llicències d'estudi del curs 20082009 dels professors Jaume Pont i Montserrat Enrech, "Adequació del projecte Física en Context al nou Currículum de Batxillerat" (Enrech i Pont, 2011), en les que es va fer l'adaptació de la "Física en Context" al nou currículum. 


\section{La Física en Context, actualment}

El projecte actual és una evolució natural de tot el procés dut a terme durant aquests anys, procés que ha permès adequar els materials a la realitat del nostre país i desvincular-los totalment de l'adaptació original lligada als materials Salters-Horners de la Universitat de York. La proposta metodològica d'aquest projecte permet assolir diferents objectius, entre els que podem destacar:

- Desenvolupament competencial. Aquests materials permeten un desenvolupament integrador i transversal de les competències del Batxillerat.

- Atenció a la diversitat. Els materials generats són de tipus diferents, permetent en tot moment l'atenció a la diversitat a l'aula, promovent especialment una Física atractiva que estimuli i desvetlli futures vocacions en aquesta àrea de coneixement.

La Física en Context és un projecte totalment adaptat al currículum oficial de la matèria de modalitat de Física de Batxillerat. A l'hora de temporitzar, el currículum s'ha estructurat en deu unitats didàctiques que cobreixen tot el currículum de la matèri-

\section{Física en context}

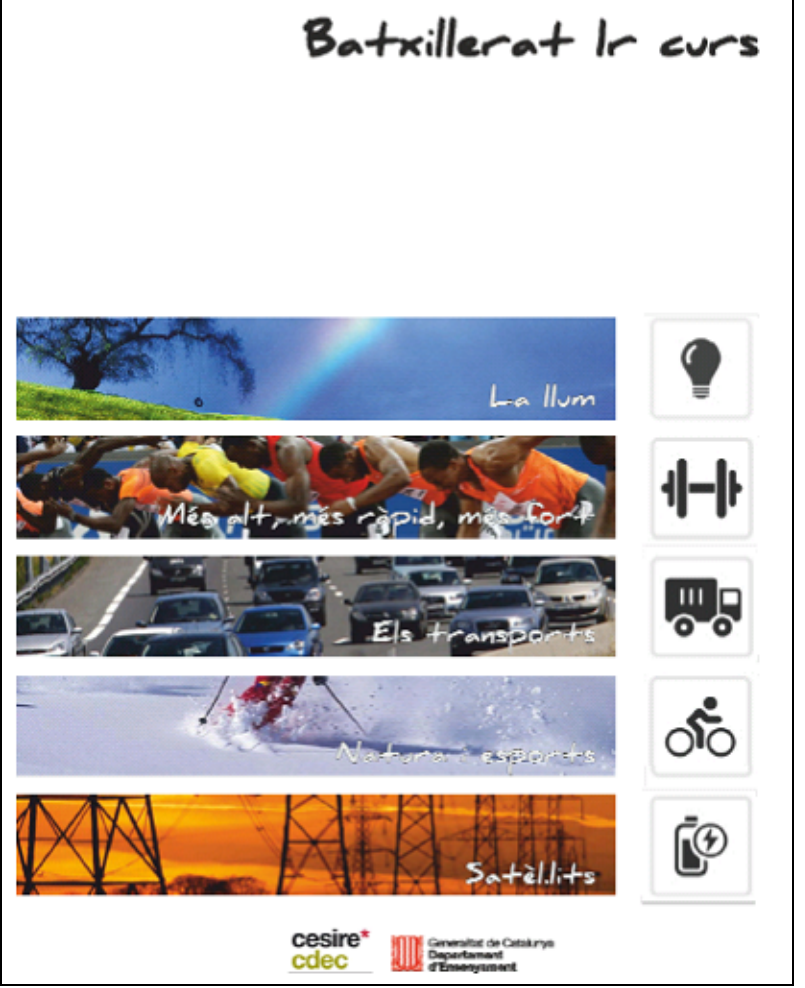

a del Batxillerat. Cada una inclou el marc teòric necessari així com les diferents activitats proposades per tal de garantir un treball competencial i diversificat. D'aquestes deu unitats, cinc s'imparteixen a primer:

- Unitat 1: La llum

- Unitat 2: Més alt, més ràpid, més fort

- Unitat 3: Transports

- Unitat 4: Natura i esports

- Unitat 5: Satèl-lits a l'espai

i cinc més a segon:

- Unitat 6: Música i so

- Unitat 7: Planetes i estrelles

- Unitat 8: Un viatge al-lucinant

- Unitat 9: Trens

- Unitat 10: Acceleradors de partícules

Cada unitat comença amb un text introductori que mostra el context de treball i avança els diferents continguts que es tractaran. Al llarg de les diferents unitats apareixen propostes d'activitats, així com exercicis amb les solucions i alguns de resolts per tal d'ajudar a l'alumnat en el seu procés d'aprenentatge. A l'acabar cada unitat es troba un apartat

\section{Física en context}
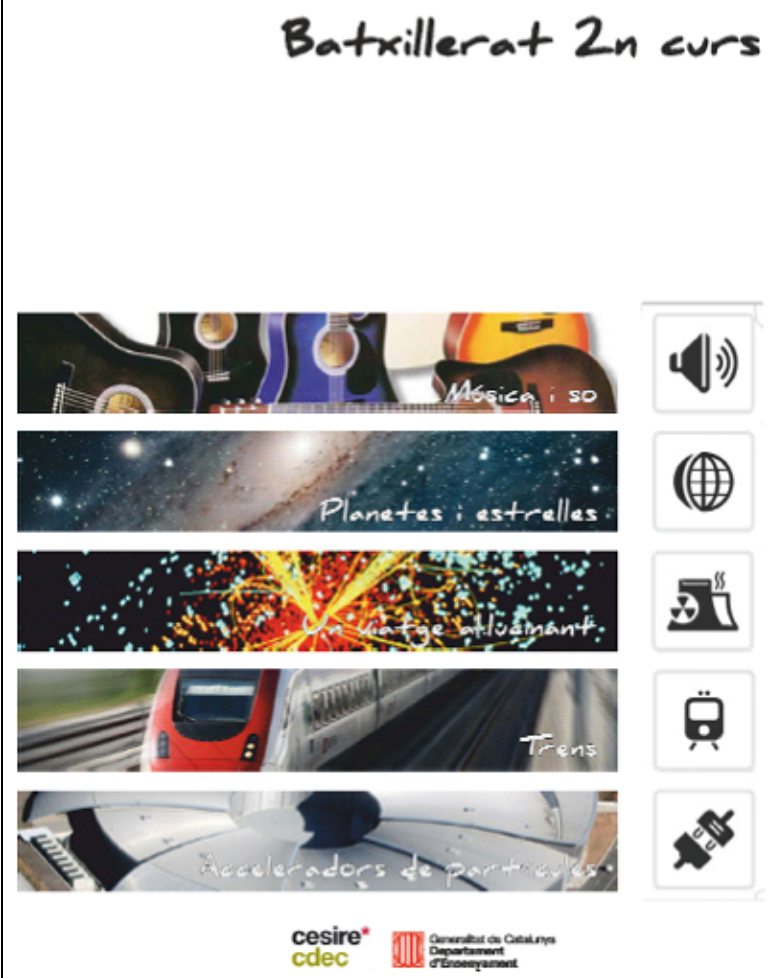
de síntesi on es proposen activitats de recapitulació i exercicis addicionals. També es recorden els objectius de la unitat perquè l'alumnat revisi el seu aprenentatge.

Les diferents unitats no constitueixen contenidors estancs. El procés d'ensenyament-aprenentatge adopta una estructura en espiral de manera que al llarg de les diferents unitats es van recordant i treballant els continguts ja estudiats. D'aquesta forma l'alumne va construint el seu propi coneixement.

\section{La digitalització}

Des del CESIRE-CDEC es considera molt important fer difusió de tots els materials ja existents dels diferents projectes de Ciència en Context (Biologia, Física i Química) per tal de donar-los a conèixer a tota la comunitat educativa i que es puguin fer servir en els centres d'ensenyament. El fet que el Departament d'Educació hagi posat en funcionament l'entorn ARC esdevé una oportunitat perquè els diferents projectes del CESIRE-CDEC $\mathrm{i}$, en concret, el projecte de Física en Context, es puguin difondre i posar a la xarxa a disposició de tothom.

Un dels problemes que es posa de manifest en les diferents reunions del grup de treball a l'hora de divulgar el material fa referència als drets d'autor. Al ser la Física en Context una adaptació d'un projecte original anglès, els materials contenen aspectes que limiten la seva difusió.

La llicència d'estudis "Adequació del projecte Física en Context a l'ARC" (2011) ha permès, amb ajuda del grup de treball del CESIRE-CDEC, elaborar les deu unitats didàctiques esmentades abans. Cada una de les unitats disposa d'una versió en paper i d'una versió digital en un format que es totalment compatible amb un moodle i que es pot descarregar des de l'aplicatiu ARC del Departament d'Ensenyament. Existeix també un lloc web de Física en Context des del qual es poden visualitzar els diferents materials. Aquest lloc web permet el treball on-line sense necessitat d'utilitzar cap moodle.

Per tal d'elaborar els materials digitals s'ha optat per l'ús del programa exelearning que permet generar materials digitals compatibles amb moodle. El programari utilitzat permet l'exportació dels materials generats en diferents formats (Scorm, IMS, $h t m l . .$.$) En el nostre cas s'ha escollit el format h t m l$, compatible amb moodle, per tal d'assegurar i garantir el correcte funcionament dels enllaços interns entre les diferents pàgines de cada unitat. El format escollit també permet millor portabilitat ja que pot ser executat sense necessitat de suport per part de cap moodle, és a dir, cada unitat pot ser executada localment.

\section{El professorat que aplica el projecte}

Durant aquests anys que s'ha aplicat el projecte de Física en Context el professorat interessat ha format part d'un grup de treball o ha fet un curs de seguiment, segons el cas, al CDEC.

En els grups de treball s'han tractat de millorar aspectes del projecte relacionats amb els materials i amb la metodologia aplicada. Així, s'han buscat contextos més propers a l'alumnat de Catalunya, s'ha ampliat el nombre d'exercicis contextualitzats (un dels objectius de l'actual currículum) i s'han revisat les activitats més significatives perquè tinguin un enfocament basat en la indagació (enquiry) seguint un cicle d'aprenentatge.

Per al nou professorat els cursos realitzats tenen l'objectiu d'ajudar-lo, fent un seguiment presencial -amb reunions periòdiques mensuals- $i$ també virtual, a través del moodle del CDEC, intentant resoldre els dubtes i inseguretats que van sorgint en l'aplicació de qualsevol nou projecte i acompanyant els professors que s'han anat incorporant a aquesta nova manera de treballar.

\section{Algunes dificultats de l'aplicació del projecte}

La seva aplicació ha involucrat dificultats dignes de conèixer i que, en alguns casos, poden ser molt engrescadores. Entre elles cal destacar l'augment de temps de preparació de les classes, a causa del coneixement que s'ha de tenir dels contextos utilitzats, no només dels continguts de Física. També s'ha de tenir en compte l'ús de les TIC que es fa en algunes activitats, que implica l'acceptació d'aquesta manera de treballar i, evidentment, un coneixement del seu ús.

No hem d'oblidar que qualsevol modificació en el procés d'ensenyament-aprenentage ha de comportar ser conscients dels canvis que s'apliquen: més coneixement de la didàctica de la Física ajuda a fer-ne una aplicació més profunda. Això s'ha intentat aconseguir gràcies als seminaris sobre didàctica impartits per investigadors especialistes en nous aspectes introduïts en el projecte.

Un altre problema rellevant ha estat la dificultat que s'han trobat els alumnes a l'hora de revisar els continguts treballats en cada unitat en format digital. Com a conseqüència s'han creat documents 
imprimibles en format paper per poder-los utilitzar tant el professorat com l'alumnat. Probablement quan els futurs alumnes i professors estiguin més habituats a treballar amb l'ordinador no caldrà el suport dels materials en paper.

\section{Conclusions}

Amb aquesta experiència, que s'està portant $a$ terme des de fa vuit anys, s'ha corroborat que perquè el professorat faci canvis en el seu ensenyament s'ha d'involucrar en l'elaboració dels materials que farà servir, així com en la metodologia que utilitzarà.

És molt difícil apropiar-se d'una innovació sense una implicació activa. És per això que formar part de grups que vagin creant els seu propis materials amb l'assessorament i seguiment d'experts és fonamental per assolir els canvis perseguits.

\section{Referències}

Aplicatiu de Recobriment Curricular (ARC) CESIRE-CDEC
Enrech, M. i Pont, J. (2011). Adequació del projecte Física en Context al nou currículum de Batxillerat. Llicència d'estudis concedida pel Departament d'Ensenyament.

Física en Context

Generalitat de Catalunya (2008), Departament d'Ensenyament. Decret pel qual s'estableix el currículum de l'assignatura de Física de Batxillerat.

Herreras, L. (2007). Avaluació del procés d'implementació de l'adaptació a Catalunya del projecte Física Salters-Horners i propostes de modificació. Llicència d'estudis concedida pel Departament d'Ensenyament

Olivella, J. (2011). "Adequació del projecte Física en Context a l'aplicatiu de recobriment curricular (ARC)". Llicència d'estudis concedida pel Departament d'Ensenyament

Rocard, M. et al., (2007). Science Education NOW: A renewed Pedagogy for the Future of Europe. Commission Européenne Luxembourg: Office des publications officielles des Communautés européennes.

Science Education Group (2001). Salters Horners Advanced Physics AS and A2. Students Book and Teacher and Technician Resource Pack, Londres, Heinemann. 